\title{
Assessment and management capacities for the child health screening and intervention initiative in Visakhapatnam, India
}

KOTESWARA RAO PAGOLU ( $\nabla$ koti_au@yahoo.co.in )

Andhra University

\section{T. RAGHAVA RAO}

Andhra University

\section{Research article}

Keywords: Developmental delays, child health screening, developmental milestones, district early intervention centre, infrastructural facilities, Visakhapatnam district

Posted Date: November 20th, 2020

DOI: https://doi.org/10.21203/rs.3.rs-44265/v3

License: (c) (i) This work is licensed under a Creative Commons Attribution 4.0 International License. Read Full License 


\section{Abstract}

Background: Early detection and early intervention of diseases can significantly improve child quality of life. The most often a diagnosis of Developmental Delay (DDs) made by a doctor based on strict guidelines. The aim of present survey is to decide the commonness of the conditions screened and institutional facilities through the RBSK activity among the children going to the DEIC focus at Visakhapatnam, India.

Methods: This observational study was conducted in Visakhapatnam, District Early Intervention Centre (DEIC) one of the north coastal district of India for one year period and 6572 children aged 2 months-18 years were taken in the study. Norms were developed by the Ministry of Health and Family Welfare, India to DEIC, according to the norms the pediatrician will examine the children who came to the center. Existing manpower analysis in the center was also done. Present study was done the multivariate logistic regression analysis were done to identify the predictors for DDs.

Results: The examination of the 30 conditions screened under 4D's methodology, defects during childbirth were there in 255(3.88\%), followed by deficiencies in 239 (3.63\%) children, diseases during childhood were seen in 1277 (19.43\%) children and disabilities and DDs were seen in 4801 (73.05\%) children. From the diseases, dental caries were found in most elevated number of youngsters with 1219 (18.54\%) cases. The mostly occurring DDs are language delay $941(14.31 \%)$ children had imperfections of these were observed. On analysis of deficiencies, most extreme number of 236 (3.59\%) children was found with serious intense unhealthiness of severe acute malnutrition. Among the defects at birth, congenital deafness was the most frequently screened stipulation found in $84(1.27 \%)$ children. The post of medical officer, Psychologist and DEIC manager stayed empty all through the examination time frame.

Conclusion: In the present study we have undiagnosed that many curable diseases in children are not identified at all in a timely manner. Early intervention services on children's health are very useful and in future these services are extent for every individual child.

\section{Background}

Birth defects or intrinsic peculiarities are utilitarian or auxiliary variations from the norm including metabolic or hereditary issues present during childbirth [1]. The Global Burden of Disease (GBD) study 2013 recognized inborn abnormalities to be one of the main ten reasons for mortality in kids less than five years old [2]. As indicated by the GBD study (2017) inherent abnormalities represent the most elevated passings globally and the weight in long stretches of life lost [3]. Nations or locales that have an expanded weight of infection "India having an enormous number of newborn children conceived every year with birth defects bears a fourth of neonatal passing's worldwide". In 2013, the nation announced a neonatal death pace of 29 for every 1000 live births with a sum of 753,000 neonatal passing's detailed inside that year [4]. Public assessments of the commonness of congenital inconsistencies uncovered pervasiveness figures as high as 472177 every year [5].

By the specialized reports from Special Newborn Care Units (SNCU) assessed that $20 \%$ of released children are endured with deferrals of redevelopments and later life lasting inabilities in vision, hearing and perception [6]. Rashtriya Bal Swasthya Karyakram (RBSK) has been dispatched in 2013 by Government of India focused on early intercession administrations in kid wellbeing screening is to be accomplished through District Early Intervention Centers (DEICs) which are being built up in all areas the nation over [7]. Network location achieved by Mobile health groups and Accredited social health activists (ASHA's) and alluded to DEIC central command for complete screen, 
analyze and treat youngsters, for this inside needs to build up institutional limits like expert labor, led preparing Programs at cutting edge level for viable operationalization and diverse kind of gear. The inside offered various types of assistance like vision, intellectual, discourse, language, and dietary treatments separated from lab tests. Youngsters treated with the 30 recorded wellbeing conditions including medical procedures at tertiary level, liberated from cost.

This examination is planned to a) determine the prevalence of the conditions screened through the RBSK initiative among the children going to the DEIC focus at Visakhapatnam area b) determine institutional and management capacities to provide child health screening and mediation administrations; and c) staff training capacities of fundamental level and progressed level for productive operationalization of birth defects.

\section{Methods}

It was a cross-sectional investigation directed at DEIC, Visakhapatnam of South India from December 2018 to December 2019. The rundown of children selected at DEIC, Visakhapatnam was acquired from separate focus with the earlier authorization by the medical officer. The investigation populace was shaped by the children with any of the 30 conditions alluded to DEIC from the fringe RBSK units, essential medical services units, network medical care units, region emergency clinics, children distinguished at conveyance point screening in the emergency clinic, kids alluded structure the pediatric out-tolerant center and furthermore kids who please their own alongside their folks/parental figures. On advent at DEIC, pediatrician were screened the children as per RBSK outfitted course of action and suitable treatment was given. The test comprised of children enlisted at the chose DEIC and examining was done and children were isolated into four age gatherings ( $<6$ weeks, 6 Weeks to 3 years, 3 to 6 years and 6 to 18 years), the children were chosen by the layers gatherings, along these lines in every layers the same number of children as come were set. In the investigation recurrence examination was done in information assortment and testing. Consequently, the example size came out to be 6572 children selected the investigation. The contrast among male and female was additionally watched, Pattern of referral, 4D Conditions screened, carefully treated conditions and an investigation of the institutional offices accessible during the examination time frame were classified.

Subjective and quantitative examination philosophies were utilized to evaluate the administration rehearses on (developmental delays) DD's at the chosen health facilities, with this expressive measurements were introduced in the recurrence with rates (for downright data). The study instruments were office agenda; record survey for specific administrations over the most recent one year; and semi-organized schedule of interview for administration providers. The system incorporated the basics as set somewhere around the setting up and working of a DEIC is unmistakably given by RBSK [8]. Security and privacy was kept up during and after the review. Information passage and investigation were done inSPSS Software Version 19 (SPSS South Asia Pvt. Ltd, Banglore, Karnataka).

\section{Result}

During the investigation time frame, 6572 children who went to the DEIC were found to have one of the 30 conditions under 4D's methodology of screening. From the results tabulated in Figure-1, of the total 6572 children who were classified under the 4D's at the DEIC during the investigation time frame, below 6 weeks age children are 940 , out of that males are 508 and females are 432. The age gathering of about a month and a half to 3 years kids screened in a year is 1457, of which 869 are guys and 588 are females, and in long term to long term bunch all out 
screened children are 1122 in which 647 are males and 475 are females. A sum of 3053 children between 6 years to 18 years old announced at the inside during study period, involving 1640 male and 1413 females.

Figure-2 shows the examination of the 30 conditions screened under 4D's methodology, defects during childbirth were there in 255 (3.88\%) children followed by deficiencies in 239 (3.63\%) children, diseases during childhood were seen in 1277 (19.43\%) children and disabilities and DDs were seen in 4801 (73.05\%) children. Figure-3 illustrates that the kids drew nearer to the DEIC Center from an assortment of ways like 3895 (59.26\%) mobile health groups, 859 (13.07\%) delivery points and 1818 (27.66\%) self-referral.

Figure-4 specifies the HR accessible at DEIC. On investigation of the institutional facilities accessible in the DEIC, the posts of pediatrician, dental specialist, physiotherapist, optometrist, audiologist cum speech therapist, early interventionist cum exceptional instructor, lab technician, staff nurture 1, staff nurture 2 and social worker were involved all through the examination time frame. The post of medical officer/clinical official, Psychologist and DEIC manager stayed empty all through the examination time frame. The administrations of dental hygienist were regularly not accessible during the investigation time frame. There were regular renunciations and new arrangements in this post in any event, during the past. The current DEIC Staff was all around prepared in fundamental and progressed levels for arranging the middle. Regarding the basic level training observational skills, proper usage and good understanding of tool assessment and developmental screening, techniques of intervention, ongoing evaluation and efficiently communication of results to professionals and families, good rapport maintains with both children and parents and knowledge on early development. As regards the advanced level training, specific to the concerned training is given. These are developmental assessment for psychologist and vision related information for optometrist.

The infrastructural amenities, for example, furniture, hardware for physiotherapy/word related treatment, dental gear, clinical hardware, Toys for play territory and tangible coordination gear were accessible, which were given by the RBSK, kid wellbeing screening and early intercession benefits under NHM program, Government of India. The symptomatic hardware, for example, streak retinoscope for vision hindrance and INCLEN indicative apparatus for epilepsy (INDT-EPI) for convulsive issues (Epilepsy) were not accessible. In the lab hardware, advanced hemoglobinometer was not in working condition during the investigation time frame.

Figure-5 indicates the significant accomplishments of this DEIC were the medical procedures accomplished for club foot, congenital cleft palate and lip, congenital cataract, congenital deafness and inborn heart maladies. Different facilities accessible in the DEIC incorporate dissemination of portable amplifiers and scenes, development hormone substitution treatment and bonding and iron chelation for thalassemia.

Graph-1 shows the quantity of kids found with birth defects. Complete 255 children had birth defects, out of which 129 were guys and 126 were females. One male offspring of about a month and a half to 3 years age bunch had neural tube imperfection, 26 children have Down's condition of which the quantity of females are more than guys, further females in the age gathering of 6-18 years are higher in number. 37 subjects of birth defects with cleft lip were accompanied with cleft palate; greatest 17 were in 0 a month and a half age bunch with more number in females. $\quad 53$ children were found to have congenital talipes equinovarus with 38 males and 15 females, a month and a half to 3 years age bunch guys are greatest in number and just 1 female child is found to have formative dysplasia of the hip. 2 kids had visual deficiency because of inborn waterfall and 84 children had congenital deafness containing 40 males and 44 females. Complete 50 children had intrinsic coronary illness including 2 male babies of 0-6 weeks, 19 offspring of about a month and a half to 3 years, 7 offspring of 3 to 6 
years and 22 offspring of 6 to 18 years age gathering. Level of inborn coronary illness altogether screened populace was $0.76 \% .1$ male infant of 0 a month and a half had retinopathy of prematurity.

Graph-2 shows the quantity of children found with deficiencies. Most extreme number of 236 children was found with serious intense unhealthiness of severe acute malnutrition. Of them a greater part of 100 children were in 3 to 6 years age gathering, with more number in males and they were treated in the healthful recovery place appended to the king George hospital medical clinic. 1 female in 6-18 years age bunch was found to have Vitamin A deficiency, 1 male child was demonstrating manifestations of Vitamin $D$ lack in about a month and a half to 3 years age gathering and 1 female child was having goiter under the age gathering of 6 years to 18 years.

Graph-3 shows the quantity of children found with diseases during childhood. Dental caries were found in most elevated number of youngsters with 1219 (18.54\%) cases. Skin maladies remains in runner up and found in 26 $(0.39 \%)$ kids. Convulsive issues were found in 20 $(0.30 \%)$ youngsters and reactive airway diseases was found in 7 kids. 5 kids with otitis media were likewise found.

Graph-4 shows the quantity of kids with developmental delays and disabilities which were found in 4801 (73.05\%) children, out of which 2742 were male and 2059 were females. 941 children had imperfections of the language delay, 917 children had hearing hindrance, 704 had learning issue and 584 had neuro-moter impairment. 505 youngsters were found with vision debilitation, 462 with motor delay, 205 kids had cognitive delay and there were $68(1.03 \%)$ instances of behavioral disorders including autism screened during the investigation time frame. RBSK has given an incredible stimulus to the treatment of children with inabilities like autism which was treated with multi model treatment including sensory integration. 4 kids were found with Attention deficit hyperactivity disorder (ADHD) and 411 kids were found to have different inabilities like growing up concerns, substance abuse, feel depressed, delay in period cycles, torment during period, agony or copying sensation while peeing and release/Foul smelling release from the genitourinary zone. All the developmental delays like language delays, cognitive delays and learning issues were determined and treated to have the assistance of Psychiatry division in the King George hospital clinic.

\section{Discussion}

RBSK program has stepped up for early detection and treatment of the imperfections during childbirth, which will yield rich profits in supporting the strength of Indian children. In our investigation of screening of children under 4D's methodology, during the examination time frame, around 255 (3.88\%) children had surrenders during childbirth, deficiencies were seen in 239 (3.63\%) youngsters, diseases during adolescence were available in 1277 (19.43\%) kids and children with disabilities/DDs are 4801 (73.05\%) out of the all out 6572 children.

In the defects at birth during childbirth, we discovered 84 congenital deafness $(1.27 \%)$ cases, which are more pervasive in the children who moved toward this middle. One of the past reports on community based disability overview upheld by Indian gathering for clinical examination (ICMR) has recognized the occurrence of innate hearing misfortune at 10/1000 in country and 20/1000 in metropolitan India [9]. Another people group based investigation by Mathers et al., likewise indicated that the ill effects of hearing misfortune was in the sixth position among the burden of diseases worldwide [10]. The second most basic malady under birth abandons was club foot found in 53 children. We found the most elevated number of club foot cases in guys in the current examination. Numerous creators have detailed already with respect to prevalence of club foot in males. Bakalis et al., announced that the occurrence of CTEV is multiple times more normal in guys contrasted with females (4:1) and it was 
factually noteworthy [11]. 50 youngsters were found with congenital heart maladies, in which most extreme were in 6-18 years age gathering and were females. Congenital heart maladies collaborators earlier announced in their examination that rate of congenital heart infections are the most continuous inborn oddities among newborn children and record for around 589479 lived globally with disability up to the year of 2017 [12]. A complete $0.56 \%$ of cleft lip and palate cases were accounted for in our examination. Our discoveries are upheld by cleft lip and palate past reports which show that the rate of 1.09 in 1000 live births of cleft lip and palate of taste are persevering in the province of Andhra Pradesh, South India [13]. In our examination we have announced an occurrence of 26 kids with down's condition. Already Gadhia pankaj et al., detailed that the serious maternal age is exemplary danger factor credited to the rates of down's condition in Western India [14]. In the current examination, two kids $(0.03 \%)$ were found with congenital cataract, in which one is male from about a month and a half to 3 years and one is female from 6-18 years age gathering. The discoveries are upheld by Limburg and Gilbert that the predominance of cataract in kids has been assessed between 7.6 out of 10,000 kids [15]. Just a single kid was found with neural tube deformity from the investigation. Cherian et al., announced that their rate of the ailment ranges from 3.39-8.88/1000 births in various areas of India [16]. One female was accounted for to have developmental dysplasia of the hip from our examination. The past report by Dezateux and Rosendahl shows that female new-conceived react to loosening up hormone delivering from maternal placenta, so they are bound to create hip displacement disorders [17].

On examination of deficiencies, the frequency of severe acute malnutrition was seen in number 236 out of 6572 children. In India, $2.8 \%$ of kids kick the bucket each year because of immediate or roundabout impact of ailing health (1 kid demise for at regular intervals) [18]. The nutritional rehabilitation center connected to this foundation in the year 2015, which is available in King George hospital, Visakhapatnam is powerful in improving the dietary status of seriously intense malnourished kids and the follow-up likewise shows the youngsters are having make up for lost time development [19]. In the current examination, lack of iodine causing goiter was found in $1 \mathrm{female}$ offspring of the age of 6-18 years. Our outcomes are upheld by the studies led by Directorate General of Health Services, which detailed that the predominance of iodine inadequacy issues is over $5 \%$ in India [20]. In our examination, one male offspring of about a month and a half to 3 years age bunch was found with Vitamin $D$ lack and one female of 6 years-18 years age bunch with Vitamin A deficiency demonstrating Bitot's spot. A past report by National Institute of Nutrition, ICMR detailed in their information that biggest piece of preschool children had subclinical Vitamin A insufficiency and are related with general medical issues [21].

In our investigation, from the child illnesses, dental caries were discovered to be exceptionally common and seen in 1219 (18.54\%) youngsters. Among them, most noteworthy number of cases was found among the children under 6-18 years age gathering. Mittal et al., upheld the discoveries of our examination demonstrating that the pervasiveness of dental caries in 5 to $\quad$ 12-year-old younger students in India were $55.5 \%$ and it hoped to $68 \%$ in the 1960 and moved to $89 \%$ in ensuing years [22]. Skin infections adding up to number of $26(0.39 \%)$ children were the second most normal illness saw among youth maladies. Our discoveries are as opposed to the past report by Tiwari et al., Madhya Pradesh, India who found that the skin illnesses (64\%) were more common than dental caries (6.8\%) [23]. The predominance shifted from study to consider contingent upon the investigation populaces. Third most basic illness in kids was convulsive disorder issues 20 (0.30\%), which are generally seen in offspring of 6-18 years age gathering. Prasad et al., likewise detailed beforehand in a network review from South India, the pervasiveness of dynamic epilepsy was high [24]. 7 reactive air way sickness cases were recognized by our examination with more number of cases in males. Beforehand the global asthma report-2018 additionally detailed that the commonness of reactive air way diseases among youngsters to be $<5$ percent in Indian sub-content [25]. 5 
number of otitis media youngsters were found in the examination. Interminable suppurative otitis media is a typical irresistible ear infection in India bringing about genuine confusions, particularly hearing hindrance [26].

On investigation of disabilities and DDs formative deferrals and incapacities, during the examination, language delay was seen to be the most elevated with 941 (14.31\%) children. Beforehand there is an examination which has depicted a high pervasiveness of language delays and detailed that discourse and language postpone was found in 42 out of 1658 kids who went to the OPD of a tertiary consideration showing medical clinic in India [27]. Hearing impedance was the second most noteworthy and was seen in 917 (13.95\%) cases. Another people group based incapacity study upholds by Garg et al. detailed that India positively faces a more terrible circumstance with respect to childhood deafness [28]. Third most predominance was learning disorder issue with 704 (10.71\%) cases, trailed by neuro-motor impairment with 584 (8.88\%) cases, vision impedance in 505 (7.68\%) cases, motor delay in $462(7.02 \%)$ cases, others (Developmental delays and disabilities) in 411 (6.25\%) cases, cognitive delay in 205 $(3.11 \%)$, autism saw in $68(1.03 \%)$ cases and attention deficit hyperactivity disorder issue in $4(0.06 \%)$ cases were appeared in the investigation. Around the world, 200 million children don't arrive at their formative potential in the initial five years due to neediness, unforeseen weakness, nourishment and absence of early incitement [29].

Institutional facilities are significant for offering quality types of assistance to the children and they incorporate labor and infrastructural facilities. The manpower examination shows that the medical officer, psychologist and DEIC manager were not accessible all through the investigation time frame. The post of dental hygienist was much of the time empty during the investigation time frame. With the help of Accredited social health activist (ASHA) workers, mobile health teams have been able to identify a large number of DD's and provide them with health support. The lack of master manpower in semi metropolitan and country areas is unfavorably influencing the treatment of kids with incapacities. Medical officer lack was dreadful effect on the sounding network and his quality in DEIC is essential in network inclusion for better administration of birth defects. All the rest of the staff from DEIC, Visakhapatnam was very much prepared by the specialized board of the Ministry of Health and Family Welfare, Government of India. On investigation of the infrastructural offices accessible during the examination time frame, we found that furnishings, hardware for physiotherapy/word related treatment, dental equipment, clinical equipment, toys for play area and sensory integration equipment were accessible. There was absence of a portion of the hardware required for distinguishing proof of the ailments like vision impairment and convulsive issues (Epilepsy). Computerized hemoglobinometer was not in working condition in the examination time frame. The total infrastructural amenities are important for top notch health frameworks. Past examinations likewise detailed that the helpless accessibility of laboratory amenities and diagnostic apparatus are additionally deterrents to quiet appraisal and finding, in any event, when suppliers know about the fundamental tests [30]. India took in this with Janani Suraksha Yojana, a money motivating force program for facility births, which hugely expanded facilitys conveyance however didn't quantifiably diminish maternal or infant mortality [31]. Great consideration is controlled by exhaustive appraisal, discovery of asymptomatic and coinciding conditions, exact finding, legitimate and convenient treatment, referral when required for medical clinic care and medical procedure, and the capacity to follow the patient and direct the therapy course varying.

\section{Conclusion}

With this examination we saw that there are numerous children who are left undiscovered and denied of opportune treatment of congenital anomalies done from part of therapeutic diseases. These children with deformities, sicknesses or inadequacies who are not recognized during the beginning phases, doesn't prompt mortality however handicap ensuing decreased personal satisfaction and expanded reliance on a parental figure. Child health 
screening and advancement of early intervention services is more significant for development in health status of children. Through RBSK, India has made a monster stride for screening and early mediation of childhood defects, ailments, inadequacies and inabilities. The interesting element of the RBSK services is the continuum of care stretching out from birth to initial 18 years old. Inspite of the dynamic advances taken, the lack of expert manpower like medical officer, psycologist and so forth, is of concern and qualified youths ought to be inspired to take up this administration situated fields as a lifelong alternative. To improve DEIC infrastructural facilities, it is important to trade the harmed gear for advancement of the program. The discoveries of the current examination will be valuable contribution for early mediation places to improve crisis activity plans in child disease supervision programs. They can likewise fill in as a standpoint for the medical care supervisors and strategy producers in their tentative arrangements and projects to confront the difficulties distinguished by early intervention habitats.

\section{Declarations}

Ethics approval and consent to participate: The study was approved by the Institutional Ethics Committee Andhra University, Visakhaptnam. Moreover present study has not involving human participants or any animal models. It is purely survey based study. "Informed consent was obtained from all individual participants included in the study". Special ethical committee permission was taken from Andhra medical college-King George hospital (AMC-KGH), visakhapatnam for the present study. Because of district DEIC running with association and monitoring of $\mathrm{KGH}$.

Consent for publication: Not applicable.

Availability of data and material (data transparency): This is an observational study done in District Early Intervention Centre (DEIC), Visakhapatnam, Andhra Pradesh, India for a period of one year. Children referred to DEIC were screened by the pediatrician as per Rashtriya Bal Swasthya Karyakram (RBSK) norms. The information of the children who attended the DEIC such as age, sex, source of referral, diagnosis, treatment given and outcome were tabulated and analyzed.

Competing interests: Not applicable.

Funding: This research was supported by a fellowship from the Indian Council of Medical Research, New Delhi, India in the form of Research Associate. The funders had no role in study design, data collection and analysis, decision to publish, or preparation of the manuscript.

Authors' contributions: Substantial contributions to the design and interpretation of data for the work. Dr.K.R.Pagolu conceptualized the study, monitored the survey and performed data analysis. Prof. T.R. Rao was the supervisor of the survey and supported to write the manuscript.

Acknowledgements: The authors would like to thank all the study participants for being part of the study and all staff at DEIC Visakhapatnam for their co-operation. The authors would also like to thank Professor and Head of Department of Community medicine, King George Hospital, Visakhapatnam for the kind cooperation and consent to execute the study.

\section{References}

1. 1. World Health Organization. Management of birth defects and haemoglobin disorders: report of a joint WHOMarch of Dimes meeting, Geneva, Switzerland.2006:17-19, 
2. Global burden of disease pediatrics collaboration. Global and national burden of diseases and injuries among children and adolescents between 1990 and 2013 findings from the global burden of disease 2013 study.

Clinical review \& education. 2016;170 (3): 267-287.

3. Breidge Boyle, Marie-Claude Addor, Larraitz Arriola, Ingeborg Barisic, Fabrizio Bianchi, Melinda CsákySzunyogh, et al. Estimating Global Burden of Disease due to congenital anomaly: an analysis of European data. Arch Dis Child Fetal Neonatal Ed., 2018; 103:22-28.

4. World Health Organization. Global health observatory data. 2015.

5. Prajkta Bhide, Anita Kar. A national estimate of the birth prevalence of congenital anomalies in India: systematic review and meta-analysis. Bhide and Kar BMC Pediatrics. 2018; 18 (175):1-10.

6. Child Health Division. First Technical Report of Special Newborn Care Units (SNCUs) in India. Operational status of special newborn care units in India. Ministry of Health and Family Welfare, New Delhi, India. 2011.

7. Rastriya Bal swasthya karyakram (RBSK). Child health Screening and intervention services under NRHM, Ministry of health and family welfare, Government of India. 2013.

8. Rashtriya Bal Swasthya Karyakram. Setting up district early intervention centers-operational guidelines. 2014.

9. ICMR Report. Collaborative study on the prevalence and etiology of hearing impairment. Indian Council of Medical Research and Department of Science \& Technology, New Delhi. 1983.

10. Mathers C, Smith A, Concha M. Global burden of hearing loss in the year 2000. Global Burden of Disease. Geneva: World Health Organization. 2000;130.

11. Bakalis S, Sairam S, Homfray T, Harrington K, Nicolaides K, Thilaganathan B. Outcome of antenatally diagnosed talipes equinovarus in an unselected obstetric population. Ultrasound Obstet Gynecol. 2002; 20:226-229.

12. GBD 2017 Congenital Heart Disease Collaborators. Global, regional, and national burden of congenital heart disease, 1990-2017: a systematic analysis for the Global Burden of Disease Study 2017. Lancet child adolesc health. 2020; 4: 185-200.

13. Reddy SG, Reddy RR, Bronkhorst EM, Prasad R, Ettema AM, Sailer HF, Bergé SJ. Incidence of cleft Lip and palate in the state of Andhra Pradesh, South India. Indian Journal of Plastic Surgery. 2010; 43(2):184-189.

14. Gadhia Pankaj, Kathiriya Avani, Vaniawala Salil. Prevalence of Down syndrome in western India: A Cytogenetic Study. British Journal of Medicine \& Medical Research. 2015; 5(10): 1255-1259.

15. Limburg H, Gilbert C, Hon do N, Dung NC, Hoang TH. Prevalence and causes of blindness in children in Vietnam. Ophthalmology. 2012; 119 (2):355-61

16. Cherian A, Seena S, Bullock RK, Antony A. Incidence of neural tube defects in the least-developed area of India: A population-based study. The Lancet. 2005; 366:930-931.

17. Dezateux C, Rosendahl K. Developmental dysplasia of the hip. Lancet. 2007; 369:1541-1552.

18. International Institute of Population Sciences. National family health survey (NFHS2), 1998-99. Mumbai: International Institute of Population Sciences. 2000.

19. Rama Rao B, Naidu SA, Kumar LS, Madhavi BD. Effectiveness of nutritional intervention measures on children admitted in nutritional rehabilitation center (NRC) King George HospitalVisakhapatnam. journal of evidence based medicine and healthcare. 2015; 2(60): 9009-9011.

20. Directorate General of Health Services. Ministry of Health \& Family Welfare, Government of India. 2016. 
21. National Nutrition Monitoring Bureau (2005-2006). Diet and Nutritional Status of Rural Population. NNMB Technical Report no.24. Hyderabad: National Institute of Nutrition, Indian Council of Medical Research. 2006.

22. Mittal M, Chaudhary P, Chopra R, Khattar V. Oral health status of 5 years and 12 years old school going children in rural Gurgaon, India: An epidemiological study. Journal of Indian Society of Pedodontics and Preventive Dentistry. 2014; 32(1): 3-8.

23. Tiwari J, Jain A, Singh Y, Soni AK. Estimation of magnitude of various health conditions under 4Ds approach, under RBSK Programme in Devendra nagar block of Panna District, Madhya Pradesh, India. International Journal of community medicine and public health. 2015; 2(3): 228-233.

24. Prasad KN, Prasad A, Verma A, Singh AK. Human cysticercosis and Indian scenario: A review. Journal of Biosciences. 2008; 33(4): 571-582.

25. Innes Asher, Nils Billo, Karen Bissell, Chiang Chen-Yuan, Philippa Ellwood, Asma El Sony, Luis García-Marcos, Guy Marks, Neil Pearce, David Strachan. The global asthma report 2018. The global asthma network. 2018.

26. Jose Acuin. Chronic suppurative otitis media-Burden of Illness and Management Options. Child and adolescent health and development prevention of blindness and deafness. World Health Organization, Geneva, Switzerland. 2004.

27. Sunderajan T, Kanhere SV. Speech and language delay in children: Prevalence and risk factors. Journal of family medicine and primary care. 2019; 8 (5): 1642-1646.

28. Garg S, Chadha S, Malhotra S, Agarwal AK. Deafness: Burden, prevention and control in India. Natl Med J India. 2009; 22:79-81.

29. Sally Grantham-McGregor, Yin Bun Cheung, Santiago Cueto, Paul Glewwe, Linda Richter, Barbara Strupp, International Child Development Steering Group. Developmental potential in the first 5 years for children in developing countries. Lancet. 2007; 369: 60-70.

30. Adesina A, Chumba D, Nelson AM, Orem J, Roberts DJ Wabinga H, Wilson M, Rebbeck TR. Improvement of pathology in sub-Saharan Africa. The Lancet Oncology. 2013; 14(4):152-157.

31. Ng M, Misra A, Diwan V, Agnani M, Levin-Rector A, De Costa A. An assessment of the impact of the JSY cash transfer program on maternal mortality reduction in Madhya Pradesh, India. Global Health Action. 2014; 7(1):110.

\section{Tables}




\begin{tabular}{|c|c|}
\hline \multicolumn{2}{|l|}{ Age and sex distribution of study group } \\
\hline \begin{tabular}{l|l} 
Age group &
\end{tabular} & Total (\%) \\
\hline $0-6$ weeks & $940(14.30)$ \\
\hline 6 weeks -3 years & $1457(22.16)$ \\
\hline 3 weeks -6 years & $1122(17.07)$ \\
\hline $6-18$ years & $3053(46.45)$ \\
\hline Total & 6572 \\
\hline \multicolumn{2}{|l|}{ Pattern of referral to DEIC } \\
\hline Place of referral & No (\%) \\
\hline $\begin{array}{l}\text { Mobile health teams } \\
\text { Health facility/Deliverv noint }\end{array}$ & $3895(59.26 \%)$ \\
\hline \multirow{2}{*}{$\begin{array}{l}\text { Health facility/Delivery point } \\
\text { Self-referral to DFIC }\end{array}$} & $859(13.07 \%)$ \\
\hline & $1818(27.66 \%)$ \\
\hline Total & 6572 \\
\hline \multicolumn{2}{|l|}{ Human Resources available in DEIC } \\
\hline Specialist & Availability \\
\hline Pediatrician & Available \\
\hline Medical Officer & Vacant \\
\hline Dental Surgeon & Available \\
\hline $\begin{array}{l}\text { Physiotherapist } \\
\text { Psycholoqist }\end{array}$ & Available \\
\hline \multirow{2}{*}{$\begin{array}{l}\text { Psychologist } \\
\text { Optometrist }\end{array}$} & Vacant \\
\hline & Available \\
\hline Audiologist cum Speech Therapist & Available \\
\hline Early Interventionist cum Special Educator & Available \\
\hline Lab technician & Available \\
\hline Dental Hygienist & Frequently Vacant \\
\hline DEIC Manager & Vacant \\
\hline $\begin{array}{c}\text { Staff Nurse } 1 \\
\text { Staff Nurse } 2\end{array}$ & Available \\
\hline \multirow{2}{*}{$\begin{array}{l}\text { Staff Nurse } 2 \\
\text { Social Worker }\end{array}$} & Available \\
\hline & Available \\
\hline Data enty operator & Available \\
\hline \multicolumn{2}{|l|}{ Infrastructural facilities available in DEIC } \\
\hline Furniture & Available \\
\hline $\begin{array}{l}\text { Equipments for Physiotherapy/Occupational } \\
\text { Therapy }\end{array}$ & Available \\
\hline $\begin{array}{l}\text { Diagnostic Equipments/Tools for Vision, Hearing } \\
\text { \& Speech, Intellectual, Emotional \& Behavioral } \\
\text { Assessment }\end{array}$ & $\begin{array}{l}\text { Streak Retinoscope for vision impairment and } \\
\text { INCLEN DIagnostic Tool for Epilepsy (INDT - } \\
\text { EPI) for Convulsive Disorders (Epilepsy) are } \\
\text { not available. }\end{array}$ \\
\hline Dental equipment & Available \\
\hline Medical Equipments & Available \\
\hline Toys For Play Area & Available \\
\hline Lab Equipments & $\begin{array}{l}\text { Digital Hemoglobinometer is not in working } \\
\text { condition. }\end{array}$ \\
\hline Sensory Integration Equipments & $\begin{array}{c}\text { Available } \\
\end{array}$ \\
\hline 4D's Conditions screened & \\
\hline Defects at birth & $255(3.88 \%)$ \\
\hline Deficiencies & $239(3.63 \%)$ \\
\hline Diseases during Childhood & $1277(19.43 \%)$ \\
\hline Developmental delays and disabilities & $4801(73.05 \%)$ \\
\hline Total & 6572 \\
\hline Conditions treated surgically & \\
\hline Condition & Surgery done (No) \\
\hline Club foot & 5 \\
\hline Cleft palate \& lip & 36 \\
\hline Congenital Cataract & 7 \\
\hline Congenital Deafness & 50 \\
\hline Congenital Heart Diseases & 27 \\
\hline
\end{tabular}




\begin{tabular}{|c|c|c|c|c|c|c|c|c|c|c|c|c|}
\hline \multirow[t]{2}{*}{ S.no } & \multirow{2}{*}{$\begin{array}{c}\text { Name of the Birth } \\
\text { defect }\end{array}$} & \multicolumn{5}{|c|}{ Male } & & \multicolumn{4}{|c|}{ Female } & \multirow[t]{2}{*}{ Total } \\
\hline & & $\begin{array}{l}0-6 \\
\text { wk }\end{array}$ & $\begin{array}{l}\text { 6wk- } \\
3 y r\end{array}$ & $\begin{array}{l}3 \mathrm{yr}- \\
6 \mathrm{yr}\end{array}$ & $\begin{array}{l}6 y{ }^{6}- \\
18 y r\end{array}$ & Total & $\begin{array}{l}0-6 \\
\text { wk }\end{array}$ & $\begin{array}{l}6 w^{-} \\
3 y r\end{array}$ & $\begin{array}{l}3 y r- \\
6 y r\end{array}$ & $\begin{array}{l}6 \mathrm{yr}- \\
18 \mathrm{yr}\end{array}$ & Total & \\
\hline 1 & Neural Tube Defect & 0 & 1 & 0 & 0 & 1 & 0 & 0 & 0 & 0 & 0 & 1 \\
\hline 2 & Down's Syndrome & 0 & 4 & 3 & 3 & 10 & 1 & 5 & 4 & 6 & 16 & 26 \\
\hline 3 & Cleft Lip \& Palate & 7 & 9 & 0 & 1 & 17 & 10 & 7 & 1 & 2 & 20 & 37 \\
\hline 4 & Club Foot & 7 & 29 & 1 & 1 & 38 & 2 & 12 & 0 & 1 & 15 & 53 \\
\hline 5 & $\begin{array}{l}\text { Developmental } \\
\text { Dysplasia of the hip }\end{array}$ & 0 & 0 & 0 & 0 & 0 & 0 & 0 & 0 & 1 & 1 & 1 \\
\hline 6 & Congenital Cataract & 0 & 1 & 0 & 0 & 1 & 0 & 0 & 0 & 1 & 1 & 2 \\
\hline 7 & $\begin{array}{l}\text { Congenital } \\
\text { Deafness }\end{array}$ & 0 & 12 & 19 & 9 & 40 & 0 & 9 & 12 & 23 & 44 & 84 \\
\hline 8 & $\begin{array}{ll}\text { Congenital } & \text { Heart } \\
\text { Diseases } & \end{array}$ & 2 & 8 & 2 & 9 & 21 & 0 & 11 & 5 & 13 & 29 & 50 \\
\hline 9 & $\begin{array}{ll}\text { Retinopathy } \\
\text { Prematurity }\end{array}$ & 1 & 0 & 0 & 0 & 1 & 0 & 0 & 0 & 0 & 0 & 1 \\
\hline Total & & 17 & 64 & 25 & 23 & 129 & 13 & 44 & 22 & 47 & 126 & 255 \\
\hline
\end{tabular}

\begin{tabular}{|c|c|c|c|c|c|c|c|c|c|c|c|c|}
\hline \multirow[t]{2}{*}{ S.no } & \multirow{2}{*}{$\begin{array}{l}\text { Name of the } \\
\text { deficiencies }\end{array}$} & \multicolumn{5}{|c|}{ Male } & & \multicolumn{4}{|c|}{ Female } & \multirow[t]{2}{*}{ Total } \\
\hline & & $\begin{array}{l}0-6 \\
\text { wk }\end{array}$ & $\begin{array}{l}\text { 6wk- } \\
3 y r\end{array}$ & $\begin{array}{l}3 y r- \\
6 y r\end{array}$ & $\begin{array}{l}6 y{ }^{6}- \\
18 y r\end{array}$ & Total & $\begin{array}{l}0-6 \\
\text { wk }\end{array}$ & $\begin{array}{l}\text { 6wk- } \\
3 y r\end{array}$ & $\begin{array}{l}3 y r- \\
6 y r\end{array}$ & $\begin{array}{l}6 y r^{-} \\
18 y r\end{array}$ & Total & \\
\hline 1 & Severe Anemia & 0 & 0 & 0 & 0 & 0 & 0 & 0 & 0 & 0 & 0 & 0 \\
\hline 2 & $\begin{array}{l}\text { Vitamin A Deficiency } \\
\text { (Bitot's spot) }\end{array}$ & 0 & 0 & 0 & 0 & 0 & 0 & 0 & 0 & 1 & 1 & 1 \\
\hline 3 & Vitamin-D Deficiency & 0 & 1 & 0 & 0 & 1 & 0 & 0 & 0 & 0 & 0 & 1 \\
\hline 4 & $\begin{array}{ll}\text { Severe } & \text { acute } \\
\text { malnutrition } & \end{array}$ & 0 & 38 & 51 & 25 & 114 & 0 & 45 & 49 & 28 & 122 & 236 \\
\hline 5 & Goiter & 0 & 0 & 0 & 0 & 0 & 0 & 0 & 0 & 1 & 1 & 1 \\
\hline Total & & 0 & 39 & 51 & 25 & 115 & 0 & 45 & 49 & 30 & 124 & 239 \\
\hline
\end{tabular}

\begin{tabular}{|c|c|c|c|c|c|c|c|c|c|c|c|c|}
\hline \multirow[t]{2}{*}{ S.no } & \multirow{2}{*}{$\begin{array}{c}\text { Name of the } \\
\text { diseases }\end{array}$} & \multicolumn{5}{|c|}{ Male } & & \multicolumn{4}{|c|}{ Female } & \multirow[t]{2}{*}{ Total } \\
\hline & & $\begin{array}{l}0-6 \\
\text { wk }\end{array}$ & $\begin{array}{l}\text { 6wk- } \\
3 y r\end{array}$ & $\begin{array}{l}3 y r- \\
6 y r\end{array}$ & $\begin{array}{l}6 \mathrm{yr}- \\
18 \mathrm{yr}\end{array}$ & Total & $\begin{array}{l}0-6 \\
\text { wk }\end{array}$ & $\begin{array}{l}6 \mathrm{wk}- \\
3 \mathrm{yr}\end{array}$ & $\begin{array}{l}3 y r- \\
6 y r\end{array}$ & $\begin{array}{l}6 y r- \\
18 y r\end{array}$ & Total & \\
\hline 1 & Skin Conditions & 0 & 3 & 1 & 10 & 14 & 0 & 2 & 3 & 7 & 12 & 26 \\
\hline 2 & Otitis Media & 0 & 1 & 0 & 0 & 1 & 0 & 0 & 1 & 3 & 4 & 5 \\
\hline 3 & $\begin{array}{l}\text { Rheumatic Heart } \\
\text { Disease }\end{array}$ & 0 & 0 & 0 & 0 & 0 & 0 & 0 & 0 & 0 & 0 & 0 \\
\hline 4 & $\begin{array}{l}\text { Reactive Airway } \\
\text { Disease }\end{array}$ & 0 & 3 & 0 & 2 & 5 & 0 & 0 & 1 & 1 & 2 & 7 \\
\hline 5 & Dental Caries & 0 & 2 & 103 & 540 & 645 & 0 & 1 & 90 & 483 & 574 & 1219 \\
\hline 6 & $\begin{array}{l}\text { Convulsive } \\
\text { Disorders } \\
\end{array}$ & 2 & 4 & 3 & 4 & 13 & 0 & 0 & 3 & 4 & 7 & 20 \\
\hline Total & & 2 & 13 & 107 & 556 & 678 & 0 & 3 & 98 & 498 & 599 & 1277 \\
\hline
\end{tabular}


Table 5: Distribution of children according to presence of developmental delays and disabilities.

\begin{tabular}{|c|c|c|c|c|c|c|c|c|c|c|c|c|}
\hline \multirow[t]{2}{*}{ S.no } & \multirow{2}{*}{$\begin{array}{c}\text { Name of the } \\
\text { developmental delays } \\
\text { and disabilities }\end{array}$} & \multicolumn{5}{|c|}{ Male } & & \multicolumn{4}{|c|}{ Female } & \multirow[t]{2}{*}{ Total } \\
\hline & & $\begin{array}{l}0-6 \\
\text { wk }\end{array}$ & $\begin{array}{l}6 w k- \\
3 y r\end{array}$ & $\begin{array}{l}3 y r- \\
6 y r\end{array}$ & $\begin{array}{l}6 y r_{-}^{-} \\
18 y r\end{array}$ & Total & $\begin{array}{l}0-6 \\
\text { wk }\end{array}$ & $\begin{array}{l}6 w k- \\
3 y r\end{array}$ & $\begin{array}{l}3 \mathrm{yr}- \\
6 \mathrm{yr}\end{array}$ & $\begin{array}{l}6 \mathrm{yr}- \\
18 \mathrm{yr}\end{array}$ & Total & \\
\hline 1 & Vision impairment & 1 & 20 & 16 & 226 & 263 & 0 & 10 & 28 & 204 & 242 & 505 \\
\hline 2 & Hearing impairment & 284 & 213 & 16 & 11 & 524 & 241 & 134 & 5 & 13 & 393 & 917 \\
\hline 3 & $\begin{array}{l}\text { Neuro } \\
\text { Motor impairment }\end{array}$ & 60 & 186 & 60 & 46 & 352 & 38 & 106 & 49 & 39 & 232 & 584 \\
\hline 4 & Motor Delay & 0 & 168 & 62 & 41 & 271 & 0 & 103 & 50 & 38 & 191 & 462 \\
\hline 5 & Cognitive Delay & 0 & 2 & 36 & 94 & 132 & 0 & 0 & 18 & 55 & 73 & 205 \\
\hline 6 & Language Delay & 0 & 127 & 232 & 190 & 549 & 0 & 120 & 133 & 139 & 392 & 941 \\
\hline 7 & $\begin{array}{l}\text { Behavior } \\
\text { Disorder (Autism) }\end{array}$ & 0 & 5 & 35 & 7 & 47 & 0 & 0 & 19 & 2 & 21 & 68 \\
\hline 8 & Learning Disorder & 0 & 0 & 0 & 391 & 391 & 0 & 0 & 0 & 313 & 313 & 704 \\
\hline 9 & $\begin{array}{l}\text { Attention Deficit } \\
\text { Hyperactivity Disorder }\end{array}$ & 0 & 0 & 0 & 2 & 2 & 0 & 0 & 0 & 2 & 2 & 4 \\
\hline 10 & Others & 144 & 32 & 7 & 28 & 211 & 140 & 23 & 4 & 33 & 200 & 411 \\
\hline Total & & 489 & 753 & 464 & 1036 & 2742 & 419 & 496 & 306 & 838 & 2059 & 4801 \\
\hline
\end{tabular}

\section{Figures}

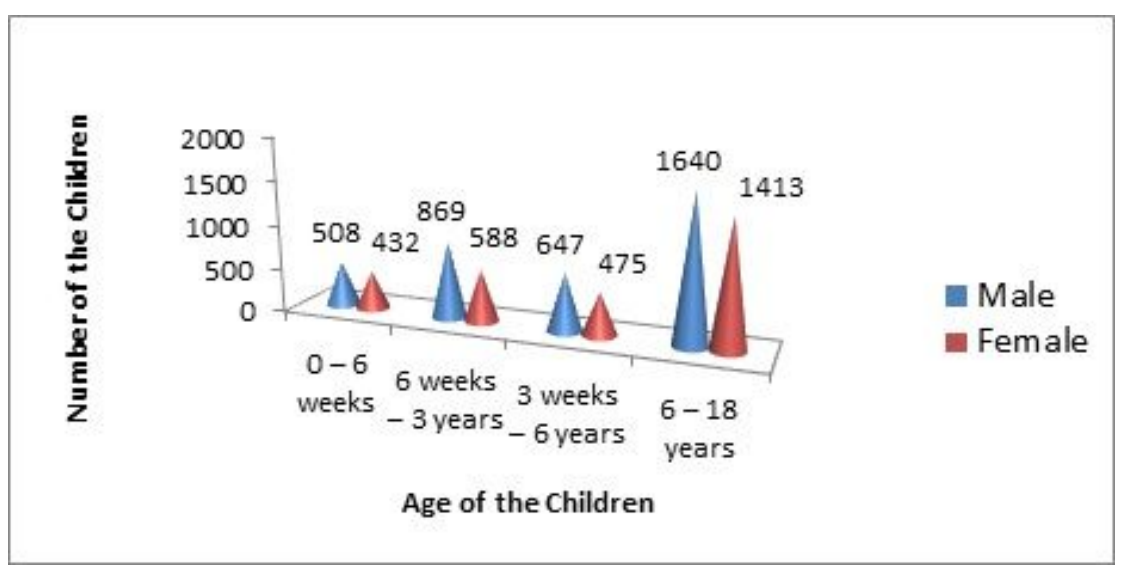

Figure 1

Profile of children attending at DEIC 


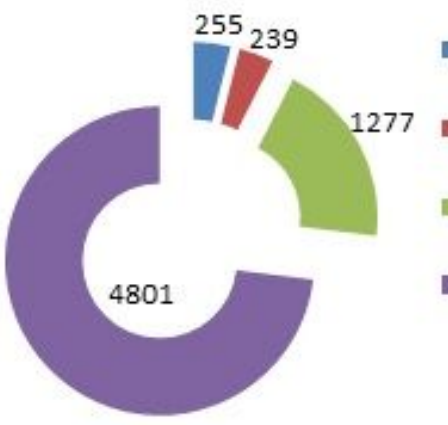

Defects at birth -255 (3.88\%)

Deficiencies - 239 (3.63\%)

Diseases during Childhood -1277 (19.43\%)

Developmental delays and disabilities - 4801 (73.05\%)

\section{Figure 2}

4D conditions screened at DEIC

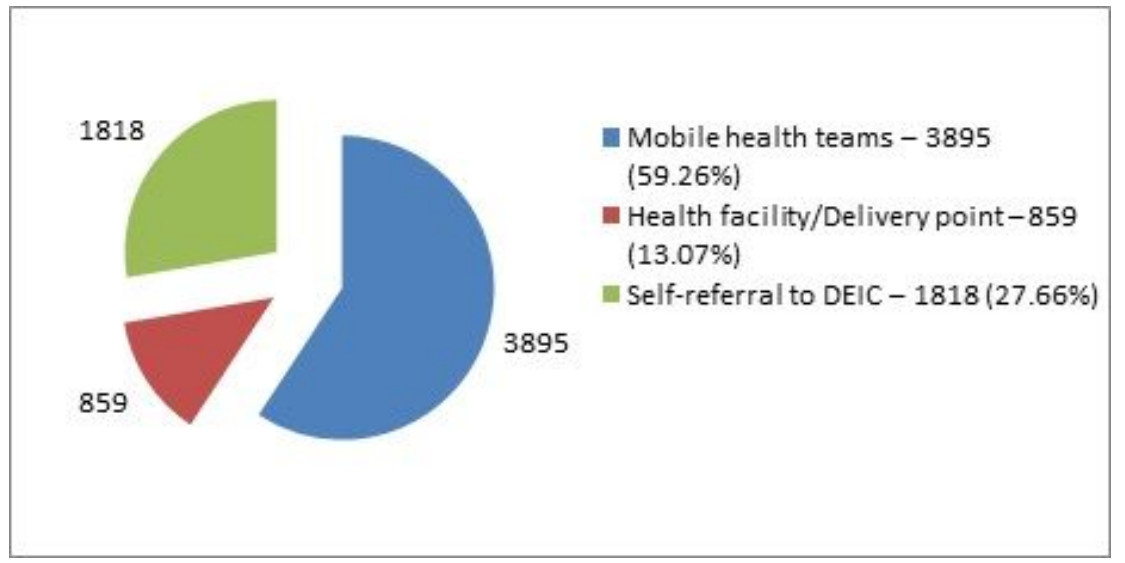

\section{Figure 3}

Pattern of referral to DEIC

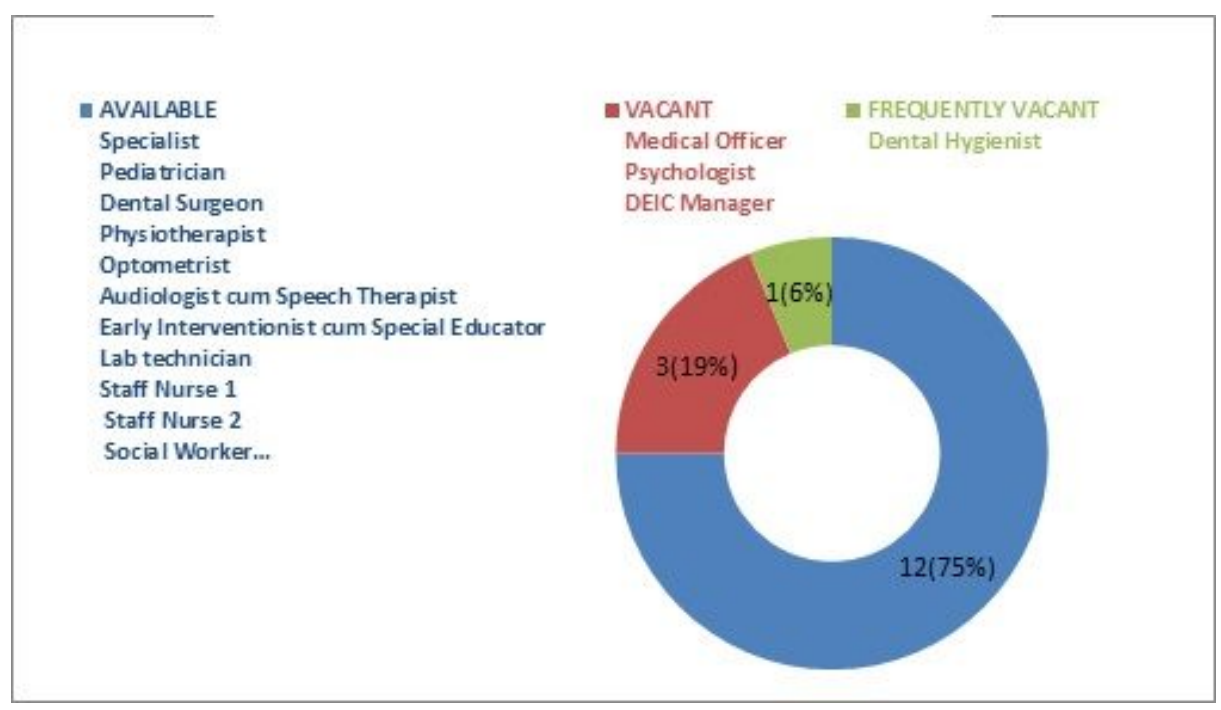

\section{Figure 4}

Human resource avilability at DEIC 


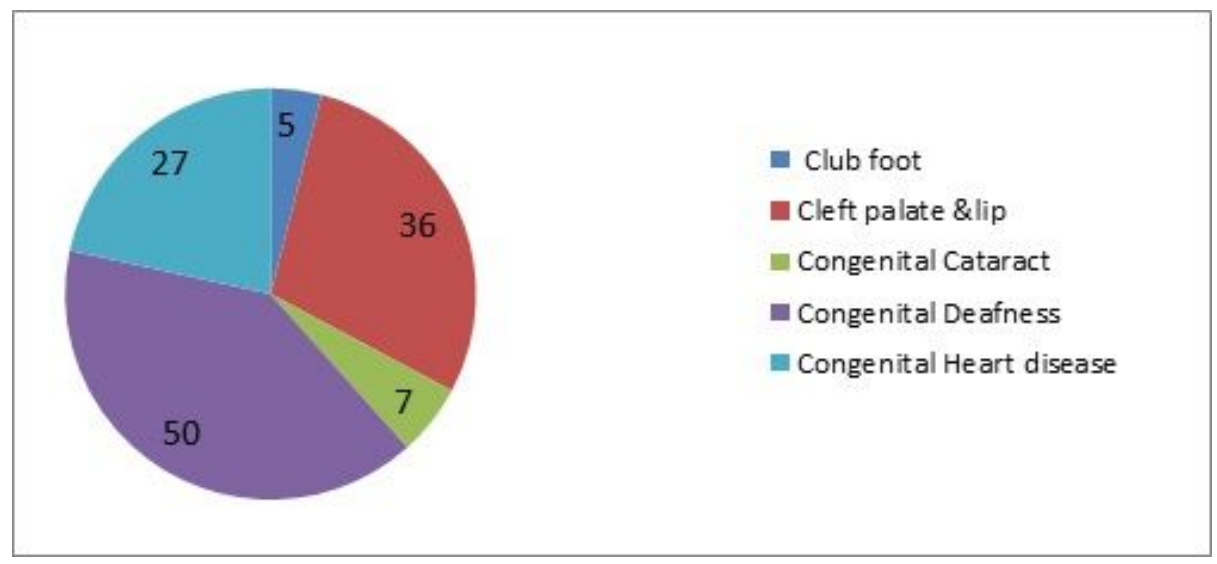

Figure 5

Medical procedures accomplished for different defects at DEIC

\section{Supplementary Files}

This is a list of supplementary files associated with this preprint. Click to download.

- Graphs.pdf 